\title{
Understanding the SARS-CoV-2 to Manage COVID-19
}

\author{
Somdatta Karak ${ }^{1}$ Vegesna Radha ${ }^{1}$ \\ ${ }^{1}$ CSIR-Centre for Cellular and Molecular Biology, Hyderabad, \\ Telangana, India
}

\begin{abstract}
Address for correspondence Somdatta Karak, CSIR-Centre for Cellular and Molecular Biology, Uppal Road, Habsiguda, Hyderabad 500 046, Telangana, India (e-mail: somdattakarak@ccmb.res.in).
\end{abstract}

Ind J Car Dis Wom:2020;5:285-293
Abstract
Keywords
- coronavirus genome
- COVID-19 testing
- COVID-19 vaccines
- disease management
- sex differences

The entire scientific community have come together in the last eight months to understand the details of the novel SARS-CoV-2 virus that has caused the COVID-19 pandemic. We now have a fair idea of the main targets that should be looked into in depth to fight the virus. However, the data from different population groups on the different testing or treatment strategies is still largely lacking. Populations are diverse in terms of their genetics, nutritional status, microbiota, access to facilities, among many other factors. This article makes a case for looking into women-specific data on test results, response to disease management strategies, as well as mortality due to COVID-19, otherwise currently missing.

\section{The Coronavirus Family}

Coronaviruses $(\mathrm{CoV})$ are RNA viruses. They contain RNA as their genetic material, surrounded by a layer of crown-like glycoproteins and a layer of lipid membrane around them.

There are hundreds of different kinds of Coronaviruses, which we know so far, found in birds and animals including humans. ${ }^{1}$ Many of them are zoonotic, ${ }^{2}$ spreading across living beings. This also opens up the possibility of these viruses being transmitted to humans from other animals. Some of the earlier known zoonotic Coronaviruses in humans have been transmitted from civet cats and dromedary camels. They have been known to be infectious and cause a range of diseases from mild cold to diseases with high mortality such as Severe Acute Respiratory Syndrome (SARS) or Middle East Respiratory Syndrome (MERS). Although not clearly understood thus far, it is thought that the zoonotic Coronaviruses cause more severe diseases.

\section{The Novel SARS-CoV-2}

SARS-CoV-2 is a novel Coronavirus that was officially reported in humans for the first time in December 2019. ${ }^{3}$ Since then, it has spread across the world, impacting people's lives and livelihoods and was declared a pandemic in March $2020 .{ }^{4}$ Comparative genome analyses of SARS-CoV-2 with
Coronaviruses from bats and pangolins show $96.2 \%$ and $91 \%$ similarity, respectively. ${ }^{5}$ These studies suggest a high possibility of the virus to have originated or come through bats and pangolins.

As in coronaviruses HCoV-NL63 and SARS-CoV, the spike (S) proteins on the surface of SARS-CoV-2 bind to the Angiotensin-Converting Enzyme-2 (ACE-2) receptors. But the binding is ten times stronger than for SARS-CoV. ${ }^{6}$ The host's transmembrane serine protease 2 (TMPRSS) cleaves the $S$ proteins to enable its binding to ACE-2, entering the host cells. ${ }^{7}$ ACE-2 expression is seen in heart, vessels, gut, lung (particularly in type-2 pneumocytes and macrophages), kidney, testis, and brain. ${ }^{8}$

The disease caused by SARS-CoV- 2 within 2 to 14 days of infection is called COVID-19. The list of symptoms of the disease includes fever, dry cough, tiredness, aches and pains, sore throat, diarrhea, conjunctivitis, headache, loss) of taste or smell, skin rashes, discoloration of finger or toes, difficulty in breathing, chest pain, and difficulty in movement. ${ }^{9}$ The chest CT scans show bilateral lung opacities after around 10 days of infection..$^{10}$ Much of the severe symptoms of COVID-19 are believed to be due to cytokine storm elicited by the hosts' immune systems. ${ }^{11}$ The immune systems have proteins such as toll-like receptors (TLRs), which are able to detect pathogen-associated molecular patterns, initiate a cascade of antiviral reactions via a set of proteins called 
cytokines. ${ }^{12}$ However, we have a limited understanding on the impact of these reactions on our own cells.

\section{Diversity in Susceptibility}

Global studies have shown elderly, those with obesity, hypertension, diabetes, and asthma, and those who are immune-compromised are found to be the most susceptible to this virus. ${ }^{13}$ Of the top 10 countries with the highest number of Coronavirus cases, India arguably shows a lower mortality rate. ${ }^{14}$ However, studies correlating the incidence and severity of the disease with various factors determined by genetic make-up among Indian populations are currently underway.

Earlier epidemics caused by SARS and MERS-CoV had affected men with worse outcomes than women. ${ }^{15,16}$ The trend remains the same in SARS-CoV-2. Women are believed to have a more superior immunity than men. ${ }^{17}$ Estrogen and testosterone act differentially on immune pathways; the former confers protection against infections, and the latter diminishes immune responses.

In the context of SARS-CoV-2 infection, lower ACE-2 reduces the risk of infection. ACE-2 has been shown to be downregulated by estrogen. ${ }^{18,19}$ Higher levels of ACE-2 has been found in men than in women in its soluble form as well as on lung epithelial cells. ${ }^{20,21}$ TMPRSS gene has an androgen-response element, which activates the transcription of this gene..$^{22,23}$ More the protease, easier will be the entry of the virus in host cells. In addition, ACE-2 gene and a variety of genes with immune functions including TLRs are expressed on X-chromosome. ${ }^{24,25}$ The two copies of X-chromosome genes in XX cells offers these cells two different allelic options. An unfavorable mutation on an X-chromosome gene in a XY cell, on the other hand, does not leave it with an alternate option. The phenomenon of $\mathrm{X}$-chromosome inactivation in $\mathrm{XX}$ cells has evolved to avoid double dosage of the genes on X-chromosome which are nonhomologous with the Y-chromosome. ${ }^{26}$ All of these put together are believed to make $\mathrm{X}$-linked diseases more common among men. The role of X-chromosome genes on SARS-CoV-2 spread and COVID-19 outcomes remains to be fully understood. ${ }^{27}$

As of May 2020, 66\% of COVID-19 cases in India cited on https://www.covid19india.org/ were males. However, the case fatality rate among women was reported to be $3.3 \%$, and $2.9 \%$ among men in India. ${ }^{28}$ This difference was more pronounced in the 40 to 49 years age group, with $3.2 \%$ women's deaths against $2.1 \%$ men's deaths. In the age group of 5 to 19 years old, it was only women who have died. Data from multiple countries have shown that a higher percentage of COVID-19 deaths have happened among infected men. ${ }^{15,29,30}$ The reason for this discrepancy in certain age groups in India remains elusive.

\section{Detecting the Virus}

Since most of the common symptoms of COVID-19 are not unique, it requires more specific molecular biology tests to confirm the viral infection.

The most widely used diagnostic test has been RT-PCR. The test allows checking for specific regions of the SARS-CoV-2 genome. The virus contains a single strand of RNA. Using reverse transcriptase (RT) enzyme, the RNA can be converted into DNA. Polymerase chain reaction (PCR) allows for amplification of select regions of the DNA.

The virus is collected from the upper respiratory tract using nasopharyngeal swabs. These swabs are then put in viral transport medium (VTM) and transferred to testing centers. We have shown that the volume of VTM can be reduced to $1 \mathrm{~mL}$ (from $3 \mathrm{~mL}$ which was otherwise used. This helps in not only saving the currently scarce reagent but also aids in concentrating the biological sample.

RNA isolation from the virus in nasopharyngeal samples require a minimum of Biosafety Level $2 \mathrm{~A}$ cabinet. ${ }^{31,32}$ It can be done manually as well as using automated machines. The procedure principally involves breaking open the virus' lipid and protein membranes using detergents, and dissolving the RNA into a buffer solution. This RNA is then converted into DNA and used for PCR generally in a qPCR machine. Since these steps do not deal with live virus, it does not need a biosafety cabinet. The qPCR machine is a thermocycler that allows for DNA amplification. The reaction is designed in a way that amplification of DNA is accompanied with increase in fluorescence, which is detected by the qPCR machine. The higher the viral load, the machine detects fluorescence in lesser number of amplification cycles, which are referred to as cycle threshold or $\mathrm{Ct}$ values.

The COVID-19 test kits contain probes to look for two or three genes in the viral genome. For $C_{t}$ values $\leq 40$ for at least two genes, the test is considered positive. These tests have shown 30 to $70 \%$ specificity across different studies, ${ }^{33-37}$ and takes 18 to 24 hours to test approximately 200 samples. Much of this time is spent on cataloguing the samples and RNA isolation.

\section{Ways to make the Testing Faster}

In areas with infection prevalence lesser than $2 \%$, we recommend pooling of five samples in one tube during RNA isolation ( - Fig. 1). Only if a pooled sample shows positive results in RT-PCR, those five samples in the pooled sample will be individually catalogued and sent for RNA isolation and individual RT-PCR.

We also found that the dry nasopharyngeal swabs can be sent to testing centers without the VTM. The biological sample from the swabs can be extracted here using a readily available buffer called Tris EDTA (TE) buffer ( - Fig. 2). This extracted sample can be also directly used in RT-PCR, skipping the RNA isolation step completely without compromising on the test's sensitivity and saving 40 to $50 \%$ of the testing costs and time. And with the step of RNA isolation from samples in TE buffer, the test's sensitivity can be improved by $20 \%$. This method of testing currently awaits ICMR approval. ${ }^{38}$

\section{Spread of Virus}

All the data on studying transmission routes of COVID-19 suggest inhalation to be the primary route of infection spread followed by surface transmission. ${ }^{39}$ 


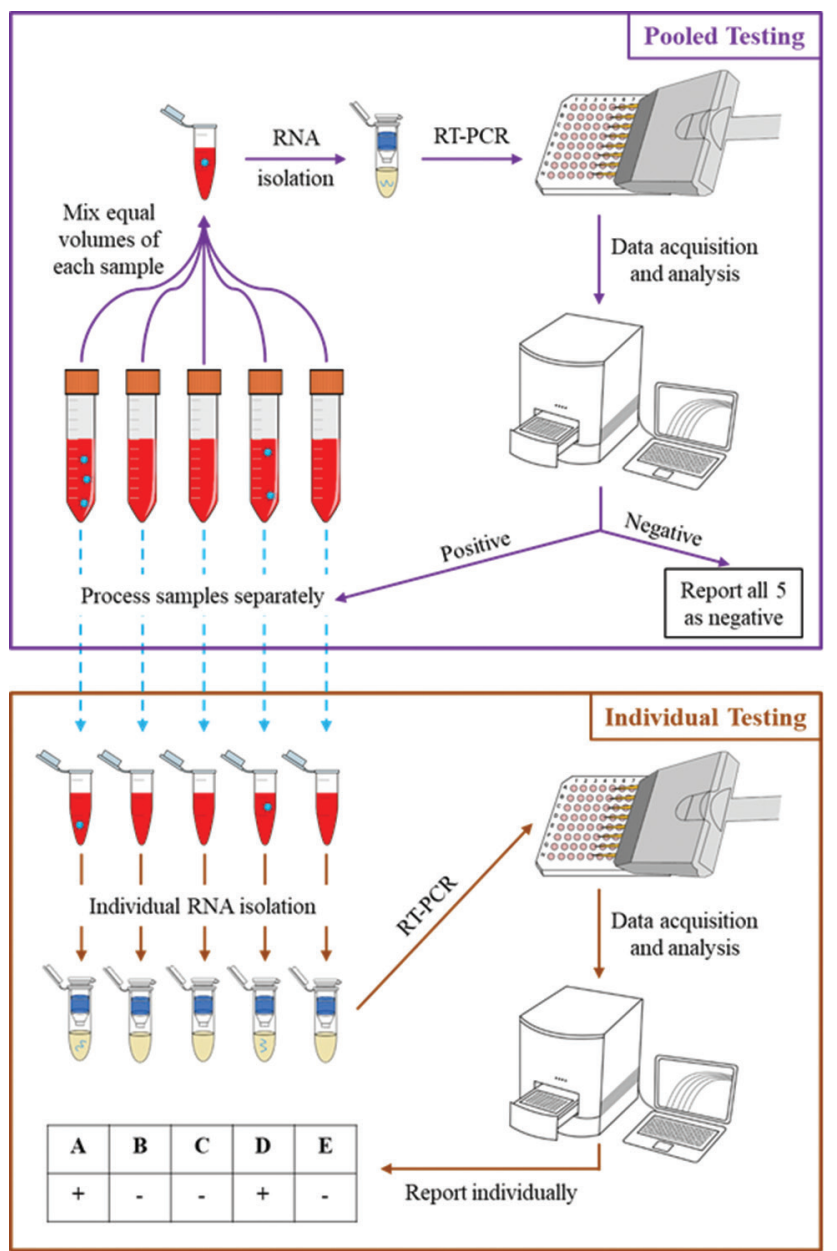

Fig. 1 Pooled testing strategy for COVID-19 diagnostics. Source: $C C M B$

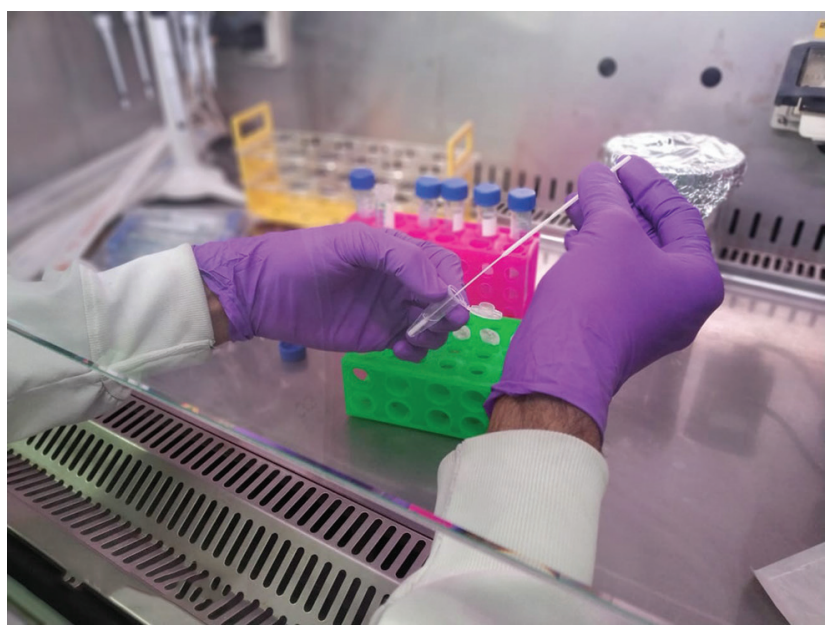

Fig. 2 Biological samples extracted from dry swabs in Tris EDTA (TE) buffer. Source: CCMB.

Latest evidence suggests a distinct possibility of airborne transmission of COVID-19. ${ }^{40,41}$ Sneezing, coughing, and even talking produces respiratory droplets (generally of sizes $5-10 \mu$ ) and droplet nuclei (of sizes $\leq 5 \mu$ ). While the respiratory droplets settle on surfaces within seconds, the smaller droplet nuclei can drift in air for a few minutes. Studies are now underway to determine how far these droplets can go and their infectivity.

\section{Genome Analysis and COVID-19 Management}

When virus spreads from one person to another, it also mutates to form strains of varied virulence. Variety in the viral genome also determines the efficiency of vaccines or drugs on each of these populations. Our genome analysis efforts along with others in the country show two major

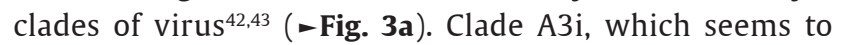
have resulted from a single outbreak in February 2020 has now almost subsided. Clade A2a is now the most dominant clade in India as well as across the globe ( - Fig. $3 \mathbf{3 b}){ }^{44,}$

Similarity in genomes of the viral populations across the world implies that the proteins expressed by the virus in different populations will also be similar to each other. This ascertains the disease management strategies targeting viral proteins, testing protocols, vaccines, and drugs, which are under development worldwide, might act equally well on all the virus populations.

Recent studies suggest that both the ancestral clades (A and B, also referred to as I and II) cause COVID-19 with no significantly different severity. ${ }^{45}$ Studies from patients in China hint at different lymphocyte levels in the earlier phase of infection, and a cytokine storm in later parts to be correlated with more severe manifestations of the disease. ${ }^{45}$ Proteome studies on patients in Germany have identified 27 proteins whose levels also alter in those with different severities of COVID-19. ${ }^{46}$

\section{Curbing the Spread}

As we are into community transmission of COVID-19, it is important for us to move into mass surveillance techniques. These will allow for communities to know the status of spread in their localities.

Centre for Cellular and Molecular Biology (CCMB) is working toward a mass surveillance strategy using next generation sequencing (NGS) facilities across the country. The strategy demands the collection centres to run PCR on the samples before shipping to nodal NGS facility. Each of these facilities can test 10,000 to 50,000 samples in a day. Through NGS, we can check for viral genes very reliably; thus, finding out persons who are currently infected.

There are rapid antigen testing kits that look for viral proteins, which are under development by various agencies and some of which have been approved by ICMR. ${ }^{47}$ These kits also use nasopharyngeal swabs but are faster and will be useful in mass surveillance of infected persons.

Antibody-based tests look for antibodies that the patient's body produces in response to an infection, which can be 

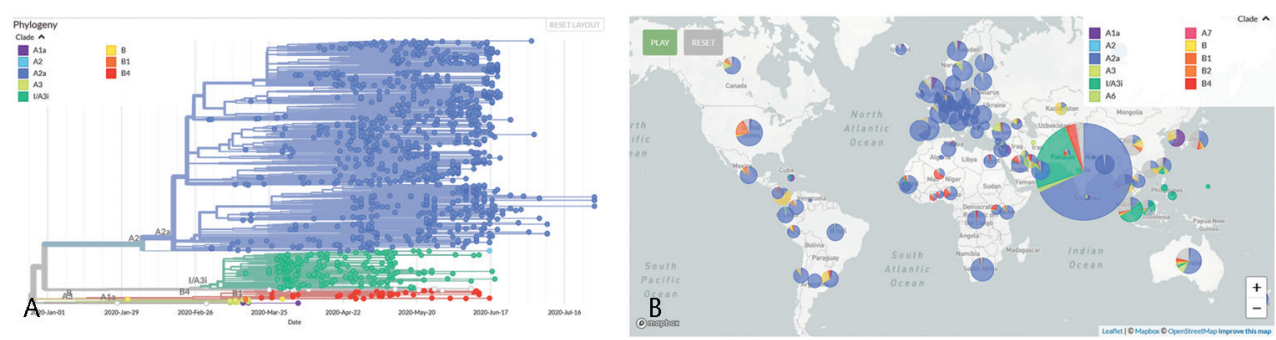

Fig. 3 (a) Spread of different clades of coronavirus in India from January to July 2020 among 1708 samples from India on Nextstrain. Source: https://data.ccmb.res.in/gear19/auspice/. (b) Proportion of different clades of coronavirus among 4397 viral samples from across the world on Nextstrain. Source: https://data.ccmb.res.in/gear19/auspice/

present for a few weeks to months. 48,49 These tests are being used, and many are under development at CCMB as well as at many other places. Testing positive in these tests implies a current or a recent infection. This will be helpful in repeated checking of large populations. We are also developing ways of checking the infection levels in localities through sewage surveillance..$^{50}$ These tests are expected to be useful in figuring out if localities have the infection and the extent of it.

Vaccines allow the body's immune system to be prepared for specific infections. Close to 200 COVID-19 vaccine candidates are in various processes of development and testing. ${ }^{51}$ The most forerunning candidate has now started its human trials. Although the vaccine trials are going through expediated processes, the first vaccine is expected to be available, if at all, by early 2021 .

The efficacy of antibody-based tests and vaccines will also depend on data from different population groups. Women, because they are known to develop higher antibody responses, might need different cutoff values in these tests or react differently to vaccines. It is imperative to systematically document the disease progression as well as effects of these interventions on women and other population groups for an overall management of the pandemic..$^{52}$

Until vaccines and mass surveillance tools are ready for use, public has its role to play. Evidence is mounting up for the effectivity of face masks in containing the spread of COVID-19. ${ }^{53}$ Handwashing with soap helps to destroy the virus particles and curbs spread by surface transmission. There have to be mechanisms of mass education on the importance of these.

\section{Way Ahead to Manage the Pandemic in India}

This crisis has allowed us all to get on war footing to identify our capabilities and push them to action. This has helped the medical staff to get familiar with molecular biology-based diagnostic tools. Scarcity of imported resources and the sheer need for large number of diagnostic kits in India has been a great impetus for medium-scale enterprises to grow. This has also helped building more portable, faster, safer, and more reliable diagnostic kits. These experiences, skills, and tools developed will find utility not only in this pandemic but also tackle many of our country-specific health issues.
It has also opened up avenues to study the biology of infections. The disease itself has raised multiple questions on the mechanisms of differential disease outcomes among the infected. ${ }^{54,55}$ This ranges from a deeper understanding of the molecular biology of coronavirus infection to different factors such as nutrition, lifestyle, microbiota, and genetics that not only differentially regulate host's immunity but also determine success of disease management strategies; much of these would be different among genders for biological as well as socioeconomic reasons. A better understanding of these in populations of different countries will help in targeted disease management.

\section{Conflicts of Interest}

None declared

\section{Acknowledgments}

We thank the COVID-19 testing and coronavirus genome sequencing and analysis teams at CSIR-CCMB for their insights with regard to their data that is in preprint.

\section{References}

1 Tyrrell DAJ, Myint SH, Coronaviruses. In: Baron S, ed Medical Microbiology 4th ed. Texas, USA: University of Texas Medical Branch at Galveston; 1996

2 Coronavirus. WHO | Regional Office for Africa. Available at: https://www.afro.who.int/publications/coronavirus. Accessed August 3, 2020

3 Chen N, Zhou M, Dong X, et al. Epidemiological and clinical characteristics of 99 cases of 2019 novel coronavirus pneumonia in Wuhan, China: a descriptive study. Lancet 2020;395(10223) : 507-513

4 WHO. | What is a pandemic? WHO. Available at: http://www. who.int/csr/disease/swineflu/frequently_asked_questions/ pandemic/en/. Accessed August 3, 2020

5 Sen S, Anand KB, Karade S, Gupta RM. Coronaviruses: origin and evolution. Med J Armed Forces India 2020 (e-pub ahead of print). doi: 10.1016/j.mjafi.2020.04.008

6 Shang J, Ye G, Shi K, et al. Structural basis of receptor recognition by SARS-CoV-2. Nature 2020;581(7807) :221-224

7 Hoffmann M, Kleine-Weber H, Schroeder S, et al. SARS-CoV-2 cell entry depends on ACE2 and TMPRSS2 and is blocked by a clinically proven protease inhibitor. Cell 2020;181(2):271-280.e8

8 Verdecchia P, Cavallini C, Spanevello A, Angeli F. The pivotal link between ACE2 deficiency and SARS-CoV-2 infection. Eur J Intern Med 2020;76:14-20 
9 Coronavirus. Available at: https://www.who.int/westernpacific/health-topics/coronavirus. Accessed August 3, 2020

10 Bernheim A, Mei X, Huang M, et al. Chest CT findings in Coronavirus disease-19 (COVID-19): relationship to duration of infection. Radiology 2020;295(3):200463

11 Ragab D, Salah Eldin H, Taeimah M, Khattab R, Salem R. The COVID-19 cytokine storm; what we know so far. Front Immunol 2020 (e-pub ahead of print). doi: 10.3389/ fimmu.2020.01446

12 Tisoncik JR, Korth MJ, Simmons CP, Farrar J, Martin TR, Katze MG. Into the eye of the cytokine storm. Microbiol Mol Biol Rev 2012;76(1):16-32

13 Zhou F, Yu T, Du R, et al. Clinical course and risk factors for mortality of adult inpatients with COVID-19 in Wuhan, China: a retrospective cohort study. Lancet 2020;395(10229): 1054-1062

14 Jain VK, Iyengar K, Vaish A, Vaishya R. Differential mortality in COVID-19 patients from India and western countries. Diabetes Metab Syndr 2020;14(5):1037-1041

15 Jin J-M, Bai P, He W, et al. Gender differences in patients with COVID-19: focus on severity and mortality. Front Public Health 2020 (e-pub ahead of print). doi: 10.3389/ fpubh.2020.00152

16 de Wit E, van Doremalen N, Falzarano D, Munster VJ. SARS and MERS: recent insights into emerging coronaviruses. Nat Rev Microbiol 2016;14(8):523-534

17 Roved J, Westerdahl H, Hasselquist D. Sex differences in immune responses: Hormonal effects, antagonistic selection, and evolutionary consequences. Horm Behav 2017;88:95-105

18 Blunting of Cardioprotective Actions of Estrogen in Female Rodent Heart Linked to Altered Expression of Cardiac Tissue Chymase and ACE2. Available at: https://www.ncbi.nlm.nih. gov/pmc/articles/PMC5805468/. Accessed August 3, 2020

19 Bukowska A, Spiller L, Wolke C, et al. Protective regulation of the ACE2/ACE gene expression by estrogen in human atrial tissue from elderly men. Exp Biol Med (Maywood) 2017;242(14):1412-1423

20 Kadel S, Kovats S. Sex hormones regulate innate immune cells and promote sex differences in respiratory virus infection. Front Immunol 2018 (e-pub ahead of print). doi: 10.3389/ fimmu.2018.01653

21 Song H, Seddighzadeh B, Cooperberg MR, Huang FW. Expression of ACE2, the SARS-CoV-2 receptor, and TMPRSS2 in prostate epithelial cells. Eur Urol 2020;78(2):296-298

22 Clinckemalie L, Spans L, Dubois V, et al. Androgen regulation of the TMPRSS2 gene and the effect of a SNP in an androgen response element. Mol Endocrinol 2013;27(12):2028-2040

23 Lucas JM, Heinlein C, Kim T, et al. The androgen-regulated protease TMPRSS2 activates a proteolytic cascade involving components of the tumor microenvironment and promotes prostate cancer metastasis. Cancer Discov 2014;4(11):1310-1325

24 O'Driscoll DN, De Santi C, McKiernan PJ, McEneaney V, Molloy EJ, Greene CM. Expression of X-linked Toll-like receptor 4 signaling genes in female vs. male neonates. Pediatr Res 2017;81(5):831-837

25 Devaux CA, Rolain J-M, Raoult D. ACE2 receptor polymorphism: Susceptibility to SARS-CoV-2, hypertension, multi-organ failure, and COVID-19 disease outcome. J Microbiol Immunol Infect 2020;53(3):425-435

$26 \mathrm{Lu} \mathrm{Z}$, Carter AC, Chang HY. Mechanistic insights in X-chromosome inactivation. Philos Trans R Soc B Biol Sci 2017;372(1733):20160356

27 van der Made CI, Simons A, Schuurs-Hoeijmakers J, et al. Presence of genetic variants among young men with severe COVID-19. JAMA 2020 (e-pub ahead of print). doi: 10.1001/ jama.2020.13719
28 Joe W, Kumar A, Rajpal S, Mishra US, Subramanian SV. Equal risk, unequal burden? Gender differentials in COVID-19 mortality in India. J Glob Health Sci 2020 (e-pub ahead of print). doi: 10.35500/jghs.2020.2.e17

29 COVID-19 Mortality Rates by Age and Gender: Why Is the Disease Killing More Men than Women? Available at: https:// rgare.com/knowledge-center/media/research/covid-19-mortality-rates-by-age-and-gender-why-is-the-disease-killingmore-men-than-women. Accessed August 3, 2020

30 ICNARC. Reports. Available at: https://www.icnarc.org/OurAudit/Audits/Cmp/Reports. Accessed August 3, 2020

31 CDC. Information for Laboratories about Coronavirus (COVID-19). Available at: https://www.cdc.gov/coronavirus/2019-ncov/lab/lab-biosafety-guidelines.html. Accessed August 3, 2020

32 Mourya DT, Sapkal G, Yadav PD, M Belani SK, Shete A, Gupta N. Biorisk assessment for infrastructure \& biosafety requirements for the laboratories providing coronavirus SARS-CoV-2/(COVID-19) diagnosis. Indian J Med Res 2020;151(2 \& 3) :172-176

33 Tahamtan A, Ardebili A. Real-time RT-PCR in COVID-19 detection: issues affecting the results. Expert Rev Mol Diagn 2020;20(5):453-454

34 Woloshin S, Patel N, Kesselheim AS, False negative tests for SARS-CoV-2 infection - Challenges and implications N Engl J Med 2020 (e-pub ahead of print). doi: 10.1056/NEJMp2015897

35 Zhao J, Yuan $\mathrm{Q}$, Wang $\mathrm{H}$, et al. Antibody responses to SARS-CoV-2 in patients of novel coronavirus disease 2019. Clin Infect Dis 2020 (e-pub ahead of print). doi:10.1093/cid/ ciaa344

36 Li Y, Yao L, Li J, et al. Stability issues of RT-PCR testing of SARS-CoV-2 for hospitalized patients clinically diagnosed with COVID-19. J Med Virol 2020;92(7):903-908

37 Detection of SARS-CoV-2 in Different Types of Clinical Specimens. Available at: https://pubmed.ncbi.nlm.nih. gov/32159775/. Accessed August 4, 2020

38 Kiran U, Gokulan CG, Kuncha SK, et al. Improved and simplified diagnosis of Covid-19 using TE extraction from dry swabs bioRxiv2020 (e-pub ahead of print). doi $10.1101 / 2020.05 .31 .126342$

39 Transmission of SARS-CoV-2: Implications for Infection Prevention Precautions. Available at: https://www. who.int/news-room/commentaries/detail/transmission-of-sars-cov-2-implications-for-infection-prevention-precautions. Accessed August 4, 2020

40 Stadnytskyi V, Bax CE, Bax A, Anfinrud P. The airborne lifetime of small speech droplets and their potential importance in SARS-CoV-2 transmission. Proc Natl Acad Sci U S A 2020;117(22):11875-11877

41 Zhang R, Li Y, Zhang AL, Wang Y, Molina MJ. Identifying airborne transmission as the dominant route for the spread of COVID-19. Proc Natl Acad Sci US A 2020;117(26):14857-14863

42 Banu S, Jolly B, Mukherjee P, et al A distinct phylogenetic cluster of Indian SARS-CoV-2 isolates bioRxiv2020;(e-pub ahead of print). doi: 10.1101/2020.05.31.126136

43 Bhoyar RC, Jain A, Sehgal P, et al. High throughput detection and genetic epidemiology of SARS-CoV-2 using COVIDSeq next generation sequencing. bioRxiv 2020 . doi:10.1101/2020.08.10.242677

44 Maitra A, Raghav S, Dalal A, et al. PAN-INDIA 1000 SARS-CoV-2 RNA genome sequencing reveals important insights into the outbreak. bioRxiv 2020. doi:10.1101/2020.08.03.233718

45 Zhang X, Tan Y, Ling Y, et al. Viral and host factors related to the clinical outcome of COVID-19. Nature 2020;583(7816): 437-440

46 Messner CB, Demichev V, Wendisch D, et al. Ultra-HighThroughput Clinical Proteomics Reveals Classifiers of COVID-19 Infection. Cell Syst 2020;11(1):11-24.e4 
47 Advisory on Use of Rapid Antigen Detection Test for COVID-19. https://www.icmr.gov.in/pdf/covid/strategy/Advisory_for_ rapid_antigen_test14062020.pdf. Accessed August 3, 2020

48 Bhatnagar S. Comparative evaluation of SARS-CoV-2 IgG assays in India. medRxiv 2020. doi:10.1101/2020.08.12.20173856

49 Malani A, Shah D, Kang G, et al. Seroprevalence of SARS-CoV-2 in slums and non-slums of Mumbai, India, during June 29-July 19, 2020. Epidemiology; 2020. doi:10.1101/2020.08.27.20182741

50 SARS-CoV-2 RNA concentrations in primary municipal sewage sludge as a leading indicator of COVID-19 outbreak dynamics. medRxiv 2020. Available at: https://www.medrxiv.org/conten t/10.1101/2020.05.19.20105999v2. Accessed August 17, 2020

51 Corum J, Grady D, Wee S-L, Zimmer C. Coronavirus Vaccine Tracker. The New York Times. Available at: https://www. nytimes.com/interactive/2020/science/coronavirus-vaccine-tracker.html. Accessed August 3, 2020
52 Fischinger S, Boudreau CM, Butler AL, Streeck H, Alter G. Sex differences in vaccine-induced humoral immunity. Semin Immunopathol 2019;41(2):239-249

53 Verma S, Dhanak M, Frankenfield J. Visualizing the effectiveness of face masks in obstructing respiratory jets. Phys Fluids (1994) 2020;32(6):061708

54 Dowd JB, Andriano L, Brazel DM, et al. Demographic science aids in understanding the spread and fatality rates of COVID-19. Proc Natl Acad Sci U S A 2020;117(18):9696-9698

55 Nepomuceno MR, Acosta E, Alburez-Gutierrez D, Aburto JM, Gagnon A, Turra CM. Besides population age structure, health and other demographic factors can contribute to understanding the COVID-19 burden. Proc Natl Acad Sci U S A 2020; 117(25):13881-13883 